\title{
Artrite séptica com acometimento poliarticular por Escherichia Coli em paciente com anemia falciforme: relato de caso
}

\section{Septic arthritis with polyarticular achievement by Escherichia Coli in patient with sickle cell disease: case report}

\author{
Rhavena Brasil de Andrade ${ }^{1}$. Gabriela Studart Galdino ${ }^{1,2}$. \\ 1 Universidade Federal do Ceará (UFC), Fortaleza, Ceará, Brasil. 2 Hospital Universitário Walter Cantídio (HUWC), Ceará, \\ Brasil.
}

\section{RESUMO}

Objetivos: Relatar o caso de uma paciente com anemia falciforme que desenvolveu artrite séptica de múltiplas articulações após infecção do trato urinário (ITU) por Escherichia coli. Metodologia: Revisão de prontuário e revisão da literatura. Resultados: M.A.C.S, feminino, 32 anos, portadora de anemia falciforme, apresentou quadro de dor lancinante em região lombar, que progrediu para grandes articulações, de forma assimétrica e aditiva. Após 5 dias, surgiram febre alta, edema, rubor e calor articular importantes, impossibilitando deambulação. Os exames laboratoriais iniciais sugeriam infecção bacteriana sistêmica, sendo iniciada antibioticoterapia empírica para ITU. As hemoculturas foram positivas para Escherichia coli multissensível. Foi realizada inicialmente artrocentese de cotovelo esquerdo e, diante da não melhora inicial com a antibioticoterapia, foi realizada artrostomia de ambos os cotovelos com drenagem de secreção purulenta. A cultura do líquido sinovial revelou Escherichia coli multissensível que foi tratada com Ciprofloxacino. Após 21 dias de antibioticoterapia, paciente recebeu alta hospitalar com recuperação da funcionalidade. Conclusões: Os bacilos entéricos Gram-negativos são um dos agentes mais comuns de artrite séptica na anemia falciforme. $\mathrm{O}$ quadro se associa a uma dolorosa crise vaso-oclusiva.

Palavras-chave: Artrite séptica. Anemia falciforme. Infecções do sistema urinário.

\section{ABSTRACT}

Objectives: Report the case of a patient with sickle cell anemia who developed multiple joint septic arthritis after urinary tract infection (UTI) by Escherichia coli. Methodology: Review of medical records and literature revision. Results: M.A.C.S, female, 32 years old, with sickle cell anemia, presented lancinating pain in the lumbar region, which progressed to large joints, in an asymmetrical and additive manner. After 5 days, high fever, edema, flushing and joint heat appeared, and there was no ambulation. Initial laboratory tests suggested systemic bacterial infection, and empirical antibiotic therapy for UTI was initiated. Blood cultures were positive for multisensitive Escherichia coli. The left elbow arthrocentesis was initially performed and, in the absence of initial improvement with antibiotic therapy, arthrotomy of both elbows with drainage of purulent secretion was performed. Synovial fluid culture revealed multisensitive Escherichia coli that was treated with Ciprofloxacin. After 21 days of antibiotic therapy, the patient was discharged with recovery of the functionality. Conclusions: Gram-negative enteric bacilli are one of the most common agents of septic arthritis in crisis.

Keywords: Septic arthritis. Sickle cell anemia. Urinary system infections.

Autor correspondente: Rhavena Brasil de Andrade, Rua Antônio Guedes Pessoa, 190, Padre Romualdo, Caucaia, Ceará, Brasil. CEP: 61601-313. Telefone: +55 85 98609-0328. E-mail: rhavenaandrade@hotmail.com

Conflito de interesses: Não há qualquer conflito de interesses por parte de qualquer um dos autores.

Recebido em: 22 Jan 2019; Revisado em: 09 Jul 2019; Aceito em: 30 Set 2019. 


\section{INTRODUÇÃO}

Doenças musculoesqueléticas são comuns em pacientes com anemia falciforme, acometendo tipicamente ossos e articulações. ${ }^{1,2,3}$ Isto se deve sobretudo a oclusões microvasculares devido à pouca flexibilidade das hemácias falcêmicas. ${ }^{1,2}$

\section{OBJETIVOS}

Relatar o caso de uma paciente com anemia falciforme que desenvolveu artrite séptica de múltiplas articulações após infecção do trato urinário (ITU) por Escherichia coli e analisar os principais diagnósticos diferenciais da crise de dor óssea aguda no paciente com anemia falciforme para que se possa instituir precocemente o tratamento.

\section{METODOLOGIA}

Revisão da literatura e revisão de prontuário, respeitando todos os aspectos éticos e legais impostos pelo Comitê de Ética em Pesquisa.

\section{RESULTADOS}

M.A.C.S, feminino, 32 anos, diagnosticada com anemia falciforme aos 3 anos de idade, apresentou quadro de dor lancinante em região lombar, que progrediu para grandes articulações, de forma assimétrica e aditiva, acometendo ombros, cotovelos e joelhos, sendo mais proeminente em cotovelos. Após 5 dias, surgiram febre alta, edema, rubor e calor articular importantes, impossibilitando deambulação. Os exames laboratoriais iniciais mostraram leucocitose, provas inflamatórias elevadas e disfunção renal, além de sumário de urina com leucocitúria e bacteriúria, sendo iniciada antibioticoterapia empírica para ITU com Ceftriaxona. O ultrassom de vias urinárias mostrou necrose de papila do rim direito secundária à pielonefrite.

Por ser a articulação com maior derrame articular, foi realizada artrocentese de cotovelo esquerdo e, diante da não melhora após esquema com Ceftriaxona, foi realizada artrostomia de ambos os cotovelos com drenagem de secreção purulenta. As hemoculturas e a cultura do líquido sinovial do procedimento revelaram Escherichia coli multissensível que foi tratada com Ciprofloxacino. A ressonância magnética (RNM) do cotovelo esquerdo excluiu osteomielite. A paciente obteve melhora significativa da poliartrite após uso de Ciprofloxacino e houve normalização da função renal sem necessidade de tratamento dialítico. Devido internamento prolongado e uso de dispositivos invasivos, como acesso

\section{REFERÊNCIAS}

1. Ganguly A, Boswell W, Aniq H. Musculoskeletal manifestations of sickle cell anaemia: a pictorial review. Anemia. 2011;2011:794283.

2. Hughes M, Akram Q, Reesand DC, Jones AK. Haemoglobinopathies venoso central, a paciente evoluiu posteriormente com nova infecção, sendo dessa vez de corrente sanguínea. Foi isolado na hemocultura Acinetobacter baumannii multirresistente tratado com Gentamicina e Polimixina B por 21 dias. Diante da persistência de febre, foi associado ao esquema Teicoplanina e Micafungina empiricamente. A paciente ficou afebril e obteve melhora clínica progressiva. Recebeu alta hospitalar com recuperação da funcionalidade. Retornou ao ambulatório assintomática e permanece em acompanhamento regular no Centro de Hematologia e Hemoterapia do Ceará.

As manifestações musculoesqueléticas na anemia falciforme resultam de hemácias aderentes, rígidas, que obstruem pequenos vasos, levando à isquemia de tecidos e consequente dano orgânico. ${ }^{1}$ A prevalência relatada de episódios vasooclusivos dolorosos foi de cerca de 1 episódio/paciente/ ano. Apresenta-se como dor aguda grave, lancinante, com edema da área afetada e sensibilidade à palpação óssea. ${ }^{2}$ É difícil distinguir entre crise vaso-oclusiva, infarto ósseo e osteomielite. ${ }^{2,3}$ Se há alta suspeição de infecção, o paciente deve ser submetido a punção articular (culturas são positivas em mais de 90\%). ${ }^{4}$ Tomografia computadorizada (TC) ou RNM ajudam a identificar osteomielite e/ou osteonecrose. ${ }^{3}$ A incidência de osteonecrose é de $24,5 \%$, com prevalência global de $10 \% .^{2}$ Os ossos mais comumente afetados são as cabeças femoral e umeral. ${ }^{1,2}$ Osteomielite incide em $18 \%$ dos casos e artrite séptica em 7\%. ${ }^{1}$ A alta incidência dessas condições se deve ao fato de que os pacientes falcêmicos têm mais predisposição à infecções devido à imunodeficiência secundária à autoesplenectomia. ${ }^{1,2} \mathrm{O}$ patógeno mais comum é Salmonella seguido de $S$. aureus. Menos frequentemente, o organismo causal é um bacilo entérico Gram negativo. ${ }^{3,4}$ Além disso, os pacientes com anemia falciforme podem ter doença muscular, levando à mionecrose que culmina em miofibrose. Essa condição se apresenta com fraqueza muscular proximal simétrica, dor muscular, edema e enduração da musculatura afetada. $^{2}$

\section{CONCLUSÃO}

Complicações musculoesqueléticas são comuns em pacientes com anemia falciforme. É clinicamente desafiador distinguir entre crise vaso-oclusiva, infarto ósseo e osteomielite/artrite séptica. Se há alta suspeição de infecção, o paciente deve ser submetido à punção articular. TC ou RNM devem ser realizadas. Os bacilos entéricos Gram-negativos são um dos agentes mais comuns de artrite séptica na anemia falciforme e frequentemente estão relacionados à ITU.

and the rheumatologist. Rheumatology. 2016;55(12):2109-18.

3. Hernigou P, Daltro G, Flouzat-Lachaniette CH, Roussignol X, Poignard A. Septic arthritis in adults with sickle cell disease often is associated with osteomyelitis or osteonecrosis. Clin Orthop Relat Res. 2010;468(6):1676-81. 
4. Horowitz DL, Katzap E, Horowitz S, Barilla-LaBarca ML. Approach to septic arthritis [Internet]. New York: American Academy of Family Physicians; 2011 [Acesso em: 26 fev 2019]. Disponível em: http:// www.aafp.org/afp/2011/0915/p653.html

\section{Como citar:}

Andrade RB, Galdino GS. Artrite séptica com acometimento poliarticular por Escherichia Coli em paciente com anemia falciforme: relato de caso. Rev Med UFC. 2020 abr-jun;60(2):44-46. 